by innumerable cream-coloured spots, which towards the base are arranged in parallel longitudinal rows, about seven in primaries, and six to seven in secondaries; body greenish black; the head, collar, pterygodes, and thorax spotted with silvery white; abdomen spotted with white at the base and sides; palpi and pectus spotted with white, basal segments of venter margined with white, anal segments covered by a wax-like testaceous plate; expanse of wings 3 inches 5 lines.

Darjeeling (Sadler).

Easily distinguished from $C$. maculata by its greater size, the more purplish colour of the wings, and the absence of the ochreous colouring on abdominal area of secondaries. I have named it after the author of the genus.

\title{
Family Liparide.
}

\section{Genus Dreata.}

Dreata triseriata, $n$. $\mathrm{sp}$.

đ. Nearly allied to D. subcurvifera, but larger, altogether yellower in colour, and with scarcely a trace of the two submarginal rows of black spots in secondaries.

Above, head and thorax densely hairy, bright straw-coloured; antennæ brown; primaries straw-coloured, with a subcostal, a bent central, and an arched submarginal series of larger black spots, the last two series meeting near the apex; abdomen and secondaries golden testaceous, the latter with two indistinct disco-submarginal parallel squamose blackish lines : body and wings below sordid ochraceous; sides of pectus and fringe of wings bright stramineous; expanse of wings 2 inches 6 to 9 lines.

Pulni Hills, S. India 8000 feet (A. F. Sealy). Five examples, B.M.

Mr. Sealy informs me that this species is not at all rare, and is easily captured, as it flies into the house; all the examples taken by him are males. The allied species, D. subcurvifera, Walker, is an inhabitant of Ceylon.

\section{On some new Species of Erigone from North America.} By the Rev. O. P. Cambridge, M.A., C.M.Z.S.

[Received May 4, 1875.]

\section{(Plate XLVI.)}

Since the publication of descriptions of new species of Erigone from North America (P. Z.S. 1874, p. 428, pl. lv.), Mr. J. H. Emerton has kindly sent me another small collection, containing nine additional species; one only of these (E. viaria, Bl.) is identical with any known European form, though several of the others are very closely allied to species found in England and France. One of the chief points of interest attaching to the present collection is in regard to two of the species (E. ornata and $E$. pictilis): in these an un- 
usual character is furnished in the very distinct and strongly marked pattern on the upperside of the abdomen ; very few European species, discovered hitherto, present any thing like a regular pattern, while the majority have a merely unicolorous abdomen.

I take this opportunity of again returning my kind thanks to $\mathrm{Mr}$. Emerton for allowing me to describe and figure portions of these very interesting little Spiders, and I also make bold to express a hope that through his exertions I may soon have the pleasure of making known other new forms of the same genus.

\section{Erigone persimilis, sp. n. (Flate XLVI. fig. 1.)}

Erigone atra, Cambr. P. Z. S. 1874, p. 429 (exclude synonym there quoted).

Adult male, length $1 \frac{1}{3}$ line.

This Spider is very closely allied to $E$. atra, Bl. (E. vagabunda, Westr.), resembling it (as well as some other kindred species) in size, colours, general form, and structure. Its distinctness was overlooked l. c. suprà ; it may, however, be distinguished from that species, on a closer examination, by the caput having a median longitudinal row of three distinct tooth-like tubercles, each of which is. furnished with a short bristle; the form also of the fore extremity, on the upperside of the radial joint of the palpus, differs slightly, but characteristically (see fig. $1 e$, fig. $2 g$, representing that of $E$. atra from a similar point of view); on the middle of the underside also of the radial joint in $\boldsymbol{E}$. atra is a very slight, indeed, but perceptible, rudimentary tooth, or tubercie, while no trace of it appears to exist in the present Spider; the denticulation also of the humeral joint differs, the teeth not being so even in size or distribution as in E. atra; the palpal organs appear to be very similar; but probably a lens of higher power than that under which I have been able to examine them would show some important structural differences.

An adult male was received in June 1874 from Mr. J. H. Emerton, by whom it was found at Swampscott, Boston, Massachusetts, under a stone; and a comparison recently made of the present Spider with that recorded as $E$. atra (P. Z. S. 1874, p. 429) proves the two to be identical.

Erigone dentigera, Cambr. (Plate XlVI. fig. 2.)

Erigone dentigera, Cambr. P. Z. S. 1874, p. $42 y$.

Adult male, length $1 \frac{1}{3}$ line.

This species is exceedingly nearly allied to $\boldsymbol{E}$. persimilis, as well as to $E$. atra (Bl.); but it may be distinguished by its shorter legs and palpi, the cubital and radial joints of the palpus being much shorter in proportion; the latter (radial) joint has also a distinet conical tooth near the middle of its underside; the form also of the fore extremities on the upperside of this joint differs, being narrower and more pointed, though still obtuse ; and the denticulation of the humeral joint differs, the teeth in the present species being fewer and blunter; the palpal organs also differ when viewed under a strong 
lens; figure $2 d$ represents those of the present species, and $1 c$ those of $\boldsymbol{E}$. persimilis; these two figures are taken from a sketch of each in a similar position, under a high power, by Mr. Emerton. The caput has a central longitudinal row of tuberculiform denticulations, like those of $\boldsymbol{E}$. persimilis, but of a smaller size.

Mr. Emerton remarks upon the darker and peculiar colour of this Spider when compared with $E$. persimilis; but this character, as far as it has yet been ascertained, is no certain specific criterion in the Spiders of this group; a long series of two well-known species $(E$. dentipalpis, Wid., and $E$. atra, Bl.), will furnish every variety of depth of colouring.

In regard to the present species, other minor differences are observable on a careful comparison with $\boldsymbol{E}$. persimilis and other, nearly allied, species. These differences will have to be carefully noted when the numerous Spiders of this group come to be monographed; but for the present purpose the differential characters detailed above and in P. Z.S. 1874 , p. 429, will be found sufficient for specific determination.

An adult male was received from Mr. Emerton, by whom it was found at Troy, near Boston, Maśsachusetts, U. S. A.; and a comparison of it, lately made, with the example described P.Z.S. $l$. c. shows the identity of the two. The present description notices the difference from $\boldsymbol{E}$. persimilis (Cambr.), while that in P. Z. S. $\boldsymbol{l}$. $\boldsymbol{c}$. differentiates it from $\boldsymbol{E}$. longipalpis, Sund., and some other species.

Erigone ornata, sp. n. (Plate XLVI. fig. 3.)

Adult male, length $1 \frac{1}{4}$ line.

This species is very closely aliied to Erigone pictilis (p. 396), resembling it very nearly in the pattern on the abdomen; the darker portion of it, however, is more mottled and marked with pale yellow, and an uninterrupted oblique and slightly curved stripe traverses each side. It may also be at once recognized from $E$. pictilis by the absence of the occipital elevation; the occiput being only a very little, and uniformly, gibbous, or rounded, and, when looked at from above the caput, is less compressed laterally near its lower margins. The cephalothorax is glossy, and of a deep yellow-brown colour; and the caput has a few erect hairs on its upper part, as well as some others, directed a little backwards, on the ocular area ; the height of the clypeus is half that of the facial space.

The eyes are of moderate size, and relatively not greatly different from each other; they are in the ordinary position; those of the hinder row are equidistant from each other, being separated by spaces equal to the diameter of one of the hind centrals, those of each lateral pair are obliquely placed and contiguous to each other, the fore lateral eye being larger than the hind lateral; those of the fore central pair are the smallest and darkest-coloured, near together, but not contiguous to each other, and each of them is separated from the fore lateral eye on its side by an interval equal to its diameter; the front row of eyes is much the shortest, and, looked at from above, straight.

The legs are not very long, but tolerably strong; their relative 
length appears to be $4,1,2,3$; they are of an orange-yellow colour, and are furnished with hairs and two or three short fine spines; one of these latter, on the outer side, near the middle of the tibia of each of the fourth pair, is much less strong than the corresponding one in $\boldsymbol{E}$. pictilis.

The palpi are short, and similar in colour to the legs; the cubital and radial joints are very short, but of about equal length, the latter being the stoutest; a single, rather upturned, slender bristle issues from the fore extremity on the upperside of the cubital joint; and the radial joint has its fore extremity, rather on the outer side, produced into a short apophysis, whose extremity is obtuse and bifid, or emarginate; the digital joint is large, and the palpal organs complex, very similar to those of $\boldsymbol{E}$. pictilis, but the spines and spiny processes are not so strong.

The falces are tolerably strong, but not very long; they are similar to the cephalothorax in colour, and armed with fine teeth on their inner margins, towards the extremity.

The maxilla and labium are slightly paler in colour than the falces; but their form is normal.

The sternum is heart-shaped, convex, and glossy, of a very deep reddish yellow-brown colour, and thickly clothed with longish hairs.

The abdomen is oval, and projects over the hinder slope of the cephalothorax ; its colour is blackish, with a pattern similar to that on the abdomen of $\boldsymbol{E}$. pictilis, differing slightly, as above observed. About the middle of the upperside are four small reddish impressed spots, forming a quadrangular figure, whose fore side is slightly shorter than the three others; the surface of the abdomen is thinly furnished with short hairs, and there are two or three rather strongly marked transverse curved folds just above the anal prominence; the spinners are very short and of a pale yellowish hue.

Two adult males of this Spider were received from Mr. J. H. Emerton, by whom they were found under leaves at Providence, Massachusetts, U. S. A., in November 1871.

Erigone pictilis, sp.n. (Plate XLVI, fig. 4.)

Adult male, length nearly $1 \frac{1}{2}$ line.

The cephalothorax is of a yellow-brown colour, and of ordinary general form, but the caput has its occiput a little elevated, the hinder slope of the elevation, looked at in profile, rounded and gradual, while the front slope is rather abrupt, forming (in profile) with the fore part of the caput a somewhat angular hollow ; the height of the clypeus, which is full, rounded, and slopes a little forward, exceeds half that of the facial space; the upper part of the caput is clothed with numerous bristly hairs directed forward, others of a similar nature occupying the ocular region and directed upwards and rather backwards.

The eyes are not very large, nor very unequal in size; they are placed in four pairs, or two transverse rows, of which the hinder one (looked at from the front) is strongly curved, and the foremost much the shortest and nearly straight; those of the hinder row are about 
equidistant from each other, the hind centrals being each placed immediately in front of a round shining pale-coloured tubercle; those of each lateral pair have a round shining tubercle behind them, they are contiguous to each other, and obliquely placed ; and from behind each of these pairs a longitudinal narrow indentation, fringed with a row of bristly hairs, runs backwards and obliquely upwards towards the hinder part of the occiput; the eyes of the fore central pair are smallest of the eight, near together, but not contiguous to each other, and each is separated from the fore lateral eye nearest to it by nearly the diameter of the latter.

The legs are moderate in length and strength; their relative lengths appear to be $4,1,2,3$; they are of a pale dull yellow colour, furnished with hairs and one or two fine black spines.

The palpi are short and similar in colour to the legs, except the digital joint, which is suffused with brown; the cubital and radial joints are very short; the latter is a little roundly produced at the fore extremity on its outer side, where it has a not very large pointed apophysis ; the digital joint is very large, and has a strong lobe towards the fore extremity on the outer side; the palpal organs are well developed and complex, a strong black tapering spine issues from their midst, and curving round inwards, almost encircles their fore extremity, and within its curve is a smaller spine coiled in a circular form.

The falces are rather paler in colour than the cephalothorax; they are tolerably long and strong, a little rounded in their profile-line, and divergent towards their extremities when looked at from the front; they are furnished with a few minute teeth towards their extremities on the inner margin, and close above them three bristles in a single row directed downwards.

The maxilla are of normal form, similar to the legs in colour, and furnished with some long and strong bristles towards their outer sides.

The labium is also of normal form, and (with the sternum, which is heart-shaped, convex, and bristly) is of a dark brown colour.

The abdomen is oval, tolerably convex above, and projects but very slightly over the base of the cephalothorax; almost unique hitherto among the numerous species of this genus, it has, like the foregoing species, a strong well-defined pattern on its upperside, very nearly resembling that of Amaurobius ferox (C. Koch); its colours are black and dull yellow, tinged (in four examples) with a slight reddish hue; and according as one or the other of these colours prevail, either may be described as the ground-colour. In the example now figured and described (Plate XLVI. fig 4), the ground-colour of the upperside is black, the fore half has two large yellowish patches on either side, followed by a series of slightly oblique spots or blotches of a similar colour, arranged in pairs, and diminishing in size as they approach the spinners; the sides are black, divided by an indistinct oblique yellowish gap; and the underside is dull yellowish, the central longitudinal line being clouded with a dusky hue. When the yellow prevails, the black forms a central longitudinal bar, from the hinder half of which a series of several oblique lateral bars issue on either 
side, diminishing in length towards the spinners; the abdomen is thinly clothed with short hairs.

The female resembles the male in colours and markings; but the occiput wants the bristly elevation so characteristic of the male.

Adults of both sexes of this fine and very interesting Spider, found on pine and juniper trees, were received from Mr. J. H. Emerton, by whom they were captured at Beverley, Swampscott, Boston, Massachusetts, U. S. A., in May 1874.

Erigone provida, sp.n. (Plate XLVI. fig. 5.)

Adult female, length rather more than 1 line.

The cephalothorax, falces, and sternum of this Spider are of a rather dark yellow-brown colour; the legs are brightish orange-yellow, the palpi, maxillæ, and labium dull yellow, suffused with brown; and the abdomen blackish yellow-brown, tinged with olive.

The form of the cephalothorax is of the ordinary type ; the profileline from the eyes to the thoracic junction almost level, with a slight dip or hollow close behind the occiput; the normal grooves and indentations are distinctly but not very strongly marked; and the height of the clypeus, which is a little impressed just below the eyes, is equal to half that of the facial space.

The eyes are on black spots in the usual position, of tolerable size ; and although closely grouped together, they occupy the whole width of the fore part of the caput; those of the hinder row are equidistant from each other, being separated by an interval not much, if any, greater than half the diameter of one of the central pair; those of each lateral pair (of which the foremost is the largest of the eight) are obliquely placed on a slight tubercle, and contiguous to each other; the foremost one is also contiguous (or as nearly so as possible) to the fore central eye nearest to it, the fore centrals also being contiguous to each other, and the smallest of the eight; the two pairs of lateral eyes thus form, with the fore central pair, a continuous curved line; and the interval between each of these last and the hind central eye nearest to it is equal to the diameter of the latter.

The legs are moderate in length and strength; their relative length appeared to be $4,1,2,3$; and they are furnished with hairs and slender bristles.

The falces are strong and of tolerable length, a little inclined towards the labium, and (as far as could be ascertained, though not with absolute certainty) armed with small teeth on the inner margin towards the extremity.

The palpi, maxillæ, labium, and sternum present no unusual or distinctive feature in form or structure.

The abdomen is of rather an elongate oval form, and not very convex above, nor projecting much over the base of the cephalothorax; it is of a dull greenish-black yellow-brown hue, marked (like many others) with pale lines and spots on the upperside, probably not visible except through spirit of wine; the form of the genital aperture is simple but characteristic.

Two examples of this species, which is nearly allied to $E$. cornu- 
palpis, were received from $\mathrm{Mr}$. Emerton, by whom they were found under leaves at Swampscott, Bostun, U. S. A., in March 1874.

\section{Erigone pertinens, sp.n. (Plate XLVI. fig. 6.)}

Adult male, length very nearly $1 \frac{1}{2}$ line.

The cephalothorax, falces, maxillæ, labium, and sternum of this Spider are of a yellow-brown colour, the sternum, however, being rather more suffused with brown; the colour of the legs and palpi is yellow, the digital joints of the latter yellow-brown, and the abdomen dull brownish black, with an olive hue. The cephalothorax is of ordinary general form; the profile line forms an almost uniform curve, of which the highest part is at the occiput; the normal indentations and grooves are not strongly marked, and the lateral constriction of the lower margins of the caput is very slight; the clypeus projects forwards, forming a continuous portion of the profilecurve, and its height equals half that of the facial space.

The eyes are in the ordinary position, of moderate size, and relatively not greatly different, those of the fore central pair being, as in most other species, the smallest ; those of the hinder row are equidistant from each other, the intervals separating them being equal to about an eye's diameter; those of the fore central pair are near together, but not contiguous to each other, and each is slightly over its own diameter's distance from the fore lateral on its side, and is separated from the hind central nearest to it by an interval equal to the diameter of the latter; those of each lateral pair are obliquely placed and contiguous to each other, the fore one being apparently the largest of the eight.

The legs are not very strong, but rather long; their relative length is $4,1,2,3$; they are well furnished with bairs, bristles, and longish, slender, bristle-like spines.

The palpi are short; the radial and cubital joints are of equal length, the former is the strongest, and has a curved spine-like pointed apophysis at the middle of its fore extremity, pointing downwards, outwards, and rather backwards; the outer side of the radial joint is furnished with some long bristly hairs; the digital joint is rather large, and has a small, pointed, somewhat spine-like apophysis near its base on the inner side, its point having the same direction, and not far removed from the point of that at the extremity of the radial joint; the palpal organs are prominent and complex, with corneous and spiny processes.

The falces are of moderate length and strong; each is armed with a strong tooth in front on the inner side, with apparently a small tubercular prominence underneath, near its base; they are also furnished with teeth along the inner margin of the fore half.

The form of the maxillæ, labium, and sternum is normal.

The abdomen is oval, moderately convex above, and projects fairly over the base of the cephalothorax; it is of a dull black-brown colour, tinged with olive-green, and is pretty well clothed with longish coarse hairs.

The female resembles the male in form and colours; the falces, 
however, are destitute of the single characteristic tooth on the inner side of their front surface ; and (in spirits of wine) the abdomen is pretty distinctly marked with various lines and mottlings of dull yellow, very faintly indicated in the male; the sexual aperture is furnished with a short prominent process of a characteristic form, impossible to describe clearly, and not easy to delineate certainly ; fig. $6 d$ is an attempt to represent its appearance slightly in perspective.

This species is allied to $E$. livida, Bl., as well as to $E$. subtilis (Cambr.) and others, but cannot be confused with them if the profile of the cephalothorax, the armature of the falces, and the form of the radial joint of the palpus and the palpal organs be carefully observed.

An adult of each sex was received from $\mathrm{Mr}$. Emerton, by whom they were found under a stone, below high-water mark, at Peaks Island, Boston, Massachusetts, U. S. A., in August 1873.

\section{Erigone persoluta, sp. n. (Plate XLVI. fig. 7.)}

Adult male, length rather over 1 line.

The cephalothorax, falces, and maxillæ of this Spider are of a yellow-brown colour, the margins of the cephalothorax being blackish; the legs and palpi (except the digital joints of the latter, which are yellow-brown) are of a dull orange-yellow colour; the labium and sternum are suffused with blackish brown; and the abdomen is dull black, with a strong olive-green tinge, marked (in spirits of wine) with fine pale spots and lines.

The form of the cephalothorax is of the ordinary type; looked at in profile, the line from the foremost eyes to the thoracic junction is a gentle curve with a very slight hollow at the occiput; the height of the clypeus, which is a little prominent at its lower margin, rather exceeds half that of the facial space.

The eyes are of tolerable size, and in the usual position, on black spots, but rather closely grouped together; those of the front row are very nearly contiguous to each other; those of the hind central pair are separated by an interval not quite equal to an eye's diameter, and each is separated from the hind lateral eye on its side by an interval rather less than that which divides those of the hind central pair ; those of each lateral pair are obliquely placed, contiguous to each other, and apparently the largest of the eight; each of the fore centrals is separated from the hind central eye nearest to it by a space equal to its own diameter.

The legs are of tolerable length and strength, their relative length being $4,1,2,3$; they are furnished with hairs, bristles, and a few fine spines.

The palpi are not very long, the radial and cubital joints very short, the former being the strongest ; it is largest at its fore extremity, but has no apophysis; and among other, finer hairs it has several longer and stronger bristly ones issuing from its fore extremity, near the outer side; the cubital joint has a single slightly sinuous bristle at its fore extremity, a litcle towards the outer side; the digital joint 
is large, and has its hinder extremity produced into a curved hornlike projection, its point being red-brown, apparently of a corneous nature, and directed outwards. The palpal organs are highly developed, prominent, and complex ; two bright red-brown strong corneous processes are most noticeable, one of them curved or folded in a circular form at their base on the outer side; the other, longer and stronger, issues from their inner extremity, and, running backwards, curves round their base.

The falces are moderate in length and strength ; they are directed backwards towards the labium, and are armed with a few minute teeth on their inner edge near the extremity.

The maxilla, labium, and sternum are of normal form.

The abdomen is oval, tolerably convex above, and projects fairly over the base of the cephalothorax; it is of a greenish black colour, mottled and lined with pale yellowish (when seen through spirits of wine) and thinly clothed with hairs.

The female resembles the male in colours and general characters; and the genital aperture is rather complex in its form.

This species is very nearly allied to the European form, $E$. conigera (Cambr.), but may, among other characters, be easily distinguished by the less strong and more curved process at the base of the digital joint, as well as by a quite different structure of the palpal organs.

Examples of this Spider were received from Mr. Emerton, by whom they were found under leaves at Swampscott, near Boston, U. S. A., in March 1874.

\section{Erigone cornupalpis, sp. n. (Plate XLVI. fig. 8.)}

Adult male, length $1 \frac{1}{4}$ line.

The cephalothorax, falces, and maxillæ of this Spider are of a yellow-brown colour; the legs and palpi dull orange-yellow, tinged slightly with brown; the labium and sternum dark yellow-brown; and the abdomen dull blackish, tinged with olive-green.

The form of the cephalothorax is of the ordinary type; a very slight dip or hollow is observable in the profile-line just behind the occiput; and the normal grooves and indentations are distinct, but not strongly marked; the height of the clypeus, which slightly projects, is equal to half that of the facial space.

The eyes are rather large, on black spots, and closely grouped together in the usual position; those of the hinder row are separated by as nearly as possible equal intervals of half a hind central eye's diameter ; those of each lateral pair are placed obliquely on a tubercle, the foremost of these pairs are the largest of the eight, and each is separated from the fore central eye on its side by an interval not much exceeding half the diameter of the latter; those of the fore central pair are smallest of the eight, very near, but not quite contiguous to each other.

The falces are strong and of tolerable leugth; they are very nearly vertical; and each appeared to have, on the outer side of its front surface, a longitudinal row of minute fine tooth-like spines; there are

Proc. Zool. Soc.-1875, No. XXVI. 
also several of the ordinary teeth on the inner margin towards the extremity.

The legs are tolerably long and strong; their relative length appeared to be $4,1,2,3$; and they are furnished thinly with hairs, bristles, and a spine on each of the genual and tibial joints of those of the fourth pair.

The palpi are rather short, tolerably strong, similar to the legs in colour, except the digital joint, which is of a yellow-brown hue ; the cubital joint is short, and has a single, strongish, sinuous, prominent, tapering bristle at the fore extremity of its upperside; the radial joint is of the same length as the cubital, but much stronger, being rather gibbous at its fore extremity almost all round, but most strongly in front, though there is no distinct apophysis; the digital joint is large, and has its hinder extremity produced into a longish and strong, tapering, but obtusely pointed, curved horn-like projection, the point directed outwards; there is also a large obtuse lobelike prominence on the outer side, divided into two or three lesser lobes ; the palpal organs are prominent and complex, a strong, somewhat folded, crescent-shaped, corneous process being placed at their base on the outer side; this process has a black, sharp-pointed, toothlike prominence at the middle of its strongest part.

The maxilla, labium, and sternum are of normal form.

The abdomen is oval, pretty convex above, and projects slightly over the base of the cephalothorax; it is of a dull greenish black hue, marked with pale lines and mottlings (probably not visible except in spirits of wine), and thinly clothed with hairs.

A single example was received from Mr. Emerton, by whom it was found at Brookline, Massachusetts, U. S. A., in 1870 . It is very nearly allied to Erigone retroversa (Cambr.), a French species, but is quite distinct. It is also allied to $\boldsymbol{E}$. cornigera, Bl., and $\boldsymbol{E}$. persoluta, Cambr. (ante, p. 400).

\section{Erigone multesima, n. sp. (Plate XLVI. fig. 9.)}

Adult female, length $1 \frac{2}{3}$ line.

The whole of the fore part of this Spider, including the legs and palpi, is of a bright orange-yellow colour, except the sternum, which is somewhat suffused with brown, and the abdomen is black.

The form of the cephalothorax is ordinary, and its profile-line describes a slight curve; the normal grooves and indentations are distinct, but not strongly marked; the thoracic junction is indicated by a curved blackish line, the convexity of the curve directed backwards; the clypeus is a little impressed or hollow (in profile) just below the eyes, and its height is equal to half that of the facial space.

The eyes are of moderate size and in the usual position, on black tubercles; those of the hinder row are equidistant from each other, the intervals being equal to the diameter of one of its central pair; the fore laterals are largest of the eight, and are, with the hind laterals, placed obliquely on a strongish tubercle; those of the fore central pair are smallest of the eight, very near, if not quite contiguous, to each other, and each is separated from the fore lateral eye 
on its side by an interval equal to its own diameter, and from the hind central nearest to it by an interval equal to the diameter of one of the fore laterals.

The legs are tolerably long, slender, and furnished with hairs, bristles, and a few longish fine spines on those of the fourth pair ; their relative length is $4,1,2,3$.

The falces are long and strong, slightly hollowed on the outer sides (when looked at from the front), and a little divergent at their extremities; they are armed on their inner edge, towards the extremities, with a double row of teeth, those of the front row rather long and strong, of the hinder row minute.

The maxilla are strong, a little curved, and inclined, but not very strongly, towards the labium.

The abdomen is large, oval, very convex above, and projects fairly over the base of the cephalothorax; it is black, thinly clothed with fine hairs, the spiracular plates and corpus of the epigyne (which is prominent and of characteristic form) dull yellow-brown; the extremity of the genital process is bright red-brown.

A single example of this Spider, which appears to belong to the group characterized (and probably rightly) as a separate genus by Menge, under the name Bathyphantes, was received from $\mathrm{Mr}$. Emerton, by whom it was found under a stone at Brighton, Boston, U. S. A., in April 1873.

\section{Erigone viaria.}

Neriene viaria, Bl. Spid. Great Brit. \& Ireland, p. 255, pl, xviii, fig. 171.

Erigone quisquiliarum, Westr. Araneæ Suecicæ, p. 277.

Adults of both sexes of this Spider were received from Mr. Emerton, by whom they were found under leaves at Brookline, Massachusetts, U. S. A., in March 1874. These examples present no variation what. ever from the English and continental examples of this species.

Erigone florens, sp. n. (Plate XLVI. fig. 10.)

Adult male, length $1 \frac{1}{4}$ line.

The cephalothorax of this pretty and very distinct species, as well as the palpi, falces, maxillæ, labium, and sternum, are of a bright shining orange-yellow colour ; the femora of the legs are of a similar colour, the genual, tibial, and metatarsal joints being strongly suffused with brownish black, while the tarsi are of a dusky yellowish hue, and the abdomen black. The caput has a large strong eminence, broader at the top (when looked at from the front) than at its junction with the caput itself, and divided into two large well-rounded lobes by a longitudinal depression; immediately behind each lateral pair of eyes is a large and deep indentation, or excavation, running longitudinally backwards, and running out to a point near the occiput; at the larger or fore end of this excavation is a small, round, shining, eye-like fovea or impression; the clypeus is broad, bold, and well-rounded, and prominent at its lower side, its height being about half that of the facial space; the fore 
side of the eminence on the caput, as well as the upper part of the fore extremity of the caput itself, is clothed with a few short hairs, directed forwards and downwards.

The eyes are small, placed in the usual four pairs, on black spots; those of the upper or hind central pair are placed on the fore side of the summit of the cephalic eminence, each being rather more than a diameter's distance from the longitudinal line which divides its two lobes from each other; the other three pairs (looked at either in front or sideways) form a transverse straight line at the fore extremity, on the upperside of the caput, rather exceeding in length that formed by each lateral pair and the hind central eye on its side; those of each lateral pair are placed a little obliquely on a slight tubercle ; those of the fore central pair are near together (but not contiguous to each other) on a tubercle.

The legs are long and slender, coloured as described above, and furnished with hairs, and some fine spines beneath the tibiæ of the first and second pairs; their relative length is $1,4,2,3$.

The palpi are tolerably strong and moderate in length; the cubital joint has some short spine-like bristles on its outer side, it is slightly bent downwards, and about double the length of the radial, which has its fore extremity on the upperside prominently produced into a moderately long tapering apophysis, curved downwards, and its margins fringed with hairs; the digital joint is large, and of an irregular form, and suffused with brown; it has a strong, prominent, somewhat keel-like lobe at its base on the outer side, furnished with a single row of very short, but strong, closely set, curved, spine-like bristles; the palpal organs are highly developed, prominent, and complex; a large corneous process projects from their extremity, and a strong, black, tapering spine issuing from its base curves in a circular form backwards on their outer side; in connexion with this spine, quite to its point, there is some yellowish diaphanous membrane; above the spine just noted, at the base of these organs, on their outer side, are two other large irregular corneous processes.

The falces are tolerably strong, but not very long; they are of a conical form, directed backwards towards the labium, and furnished with a few very minute teeth on the inner margin near their extremities.

The maisilla, labium, and sternum are of normal form.

The abdomen is large, of a roundish oval form, tolerably convex above, and of a glossy black colour, the spiracular plates being yellow ; it projects a little over the base of the cephalothorax, and is clothed thinly with very short hairs, its surface being thickly covered with very minute puncture-like impressions, four of a larger size forming on the middle of the upperside a rectangular figure whose fore side is shortest.

The female resembles the male in colours and general characters; but the cephalothorax is devoid of the cephalic eminence, the abdomen is more convex above, and the spines on the tibiæ (and metatarsi as well) of the first two pairs of legs are of a more marked character; the palpi have, among other hairs and bristles, a row of 
spine-like bristles round the fore extremity, on the upperside of the radial joint, forming a kind of chevaux-de-frise; the genital aperture is of a simple but characteristic form.

An adult male and twelve females were received from Mr. J. H. Emerton, by whom they were found at Ipswich, near Boston, Massachussetts, U.S. A., in June 1874.

\section{LIST OF SPECIES DESCRIBED.}

1. Erigone persimilis, sp. n., ơ, p. 394, Plate XLVI. fig. 1.

2. dentigera (Cambr.), o, p. 394, Plate XLVI. fig. 2.

3. —ornata, sp.n., on, p. 395, Plate XLVI. fig. 3.

4. pictilis, sp. n., ơ \& $q$, p. 396, Plate XLVI. fig. 4.

5. — provida, sp. n., + , p. 398, Plate XLVI. fig. 5.

6. - pertinens, sp. n., o \& ㅇ, p. 399, Plate XLVI. fig. 6.

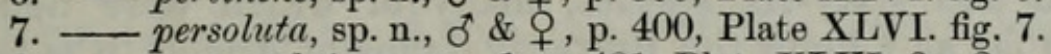

8. - cornupalpis, sp. n., ठ, p. 401, Plate XLVI. fig. 8.

9. - multesima, sp. n., $q$, p. 402, Plate XLVI. fig. 9.

10. - viaria, Bl., ơ \& 9 , p. 403.

11. - florens, sp.n., ơ \& \&, p. 403, Plate XLVI. fig. 10.

Fig. 1. Erigone persimilis ${ }^{\circ}$.

\section{EXPLANATION OF PLATE XLVI.}

$a$, part of right palpus, from the outer side; $c$, palpal organs, very highly magnified ; $e$, radial joint of right palpus, from above and behind.

2. Erigone dentigera (Camb.) ot.

$b$, part of right palpus, from outer side; $d$, palpal organs, very highly magnified ; $f$, radial joint of right palpus, from above and behind; $g$, radial joint of right palpus of Erigone atra, Bl., also from above and behind.

3. Erigone ornata o.

$a$, Spider in profile; $b$, caput and falces, from the front; $c$, upperside of Spider; $d$, left palpus, from outer side, rather in front; $e$, ditto, from inner side, also rather in front; $f$, natural length of Spider.

4. Erigone pictilis ${ }^{0}$.

$a$, Spider in profile; $b$, upperside of cephalothorax and abdomen; $c$, eaput and falces, from the front; $d$, right palpus, from outer side, rather underneath; $e$, natural length of Spider.

5. Erigone provida ․

$a$, profile of Spider; $b$, caput and falces, from the front; $c$, genital aperture; $d$, natural length of Spider.

6. Erigone pertinens 0 \& 0 .

$a$, profile $\left(\delta^{*}\right) ; b$, caput and falces $\left(\delta^{*}\right)$, from the front; $c$, right palpus $(\delta)$, from the front; $d$, genital aperture ( +$)$; $e$, natural length of Spider.

7. Erigone persoluta of \& 9 .

$a$, profile $\left(\delta^{\sigma}\right) ; b$, caput and falces $\left(\sigma^{*}\right)$, from the front; $c$, left palpus $(\delta)$, from the front, on inner side; $d$, genital aperture ( + ); $e$, natural length of Spider.

8. Erigone cornupalpis ơ.

$a$, profile; $b$, caput and falces, from the front; $c$, left palpus, from the front; $d$, right palpus on outer side in front; $e$, natural length of Spider.

9. Erigone multesima ㅇ․

$a$, profile; $b$, caput and falces, from the front; $c$, genital process; $d$, ditto, in profile; $e$, natural length of Spider.

10. Erigone florens $\delta \&$ 우.

$a$, profile $\left(\sigma^{*}\right) ; b$, caput and falces $\left(\sigma^{*}\right)$, from the front; $c$, left palpus $\left(\delta^{\sigma}\right)$ on outer side; $d$, genital aperture $(q) ; e$, natural length of Spider. 


\section{$2 \mathrm{BHL}$ Biodiversity Heritage Library}

Pickard-Cambridge, Octavius. 1875. "On some new species of Erigone from North America." Proceedings of the Zoological Society of London 1875, 393-405.

View This Item Online: https://www.biodiversitylibrary.org/item/90418

Permalink: $\underline{\text { https://www.biodiversitylibrary.org/partpdf/67158 }}$

\section{Holding Institution}

Natural History Museum Library, London

\section{Sponsored by}

Natural History Museum Library, London

\section{Copyright \& Reuse}

Copyright Status: Public domain. The BHL considers that this work is no longer under copyright protection.

This document was created from content at the Biodiversity Heritage Library, the world's largest open access digital library for biodiversity literature and archives. Visit BHL at https://www.biodiversitylibrary.org. 